\title{
Analisis Pengaruh Kompetensi Dan Motivasi Kerja Terhadap Tingkat Kepuasan Masyarakat Pada Pelayanan Terpadu Satu Pintu Kantor Kementerian Agama Kabupaten Tapin Di Rantau
}

\author{
Abdul Kadir \\ Sekolah Tinggi Ilmu Ekonomi Pancasetia Banjarmasin, Indonesia \\ Email corresponding author: audahkadir63@gmail.com
}

\begin{abstract}
ABSTRAK
Pelayanan publik oleh aparatur pemerintah dewasa ini masih banyak dijumpai kelemahan sehingga belum dapat memenuhi kualitas yang diharapkan masyarakat. Hal ini ditandai dengan masih adanya keluhan masyarakat yang disampaikan melalui media massa, sehingga dapat menimbulkan citra yang kurang baik terhadap aparatur pemerintah. dari penelitian ini adalah untuk mengetahui pengaruh kompetensi, motivasi kerja terhadap tingkat kepuasan masyarakat pada Pelayanan Terpadu Satu Pintu Kantor Kementerian Agama Kabupaten Tapin di Rantau. Metode penelitian yang digunakan adalah survey analitik Jenis penelitian adalah penelitian eksplanatory. Pengambilan sampel menggunakan teknik porpusive sampling sebanyak 93 orang. Teknik pengumpulan data menggunakan kuesioner, dokumentasi, wawancara dan observasi. Uji validitas dan reliabilitas dilakukan terhadap instrumen penelitian. Data dianalisis dengan analsis regresi linear berganda dengan uji asumsi klasik. Hasil penelitian menunjukkan bahwaKompetensi berpengaruh signifikan terhadap Kinerja Pegawai Pelayanan Terpadu Satu Pintu Kantor Kementerian Agama Kabupaten Tapin di Rantau.Motivasi Kerja berpengaruh signifikan terhadap Kinerja Pegawai Pelayanan Terpadu Satu Pintu Kantor Kementerian Agama Kabupaten Tapin di Rantau.Kompetensi berpengaruh signifikan terhadap Kepuasan masyarakat pada Pelayanan Terpadu Satu Pintu Kantor Kementerian Agama Kabupaten Tapin di Rantau.Motivasi Kerja berpengaruh signifikan terhadap Kepuasan masyarakat pada Pelayanan Terpadu Satu Pintu Kantor Kementerian Agama Kabupaten Tapin di Rantau.Kinerja Pegawai berpengaruh signifikan terhadap Kepuasan masyarakat pada Pelayanan Terpadu Satu Pintu Kantor Kementerian Agama Kabupaten Tapin di Rantau.
\end{abstract}

Kata Kunci: Kompetensi, Motivasi Kerja, tingkat kepuasan masyarakat

\section{ABSTRACT}

Currently, there are still many weaknesses in public services by government officials, so that they have not been able to meet the quality expected by the community. This is indicated by the existence of public complaints submitted through the mass media, so that it can create an unfavorable image of the government apparatus. of this study was to determine the effect of competence, work motivation on the level of community satisfaction at the One Stop Service Office of the Ministry of Religion of Tapin Regency in Rantau. The research method used is analytic survey. The type of research is explanatory research. Sampling using porpusive sampling technique as many as 93 people. Data collection techniques using questionnaires, documentation, interviews and observations. Validity and reliability tests were carried out on the research instrument. Data were analyzed by multiple linear regression analysis with classical assumption test. The results showed that competence had a significant effect on the performance of the One Stop Service Employee at the Tapin Regency Office of Religion in Rantau. Work Motivation had a significant effect on the Performance of the One Stop Service Employee at the Tapin Regency Office of the Ministry of Religion in Rantau. Competence had 
a significant effect on community satisfaction in the One Stop Service. The door of the Tapin Regency Ministry of Religion Office in Rantau. Work Motivation has a significant effect on community satisfaction at the One Stop Service of the Tapin Regency Ministry of Religion in Rantau. Employee performance has a significant effect on community satisfaction at the One Stop Service of the Tapin Regency Office of the Ministry of Religion in Rantau.

Keywords: Competence, work motivation, community satisfaction level

\section{PENDAHULUAN}

Pelayanan publik oleh aparatur pemerintah dewasa ini masih banyak dijumpai kelemahan sehingga belum dapat memenuhi kualitas yang diharapkan masyarakat. Hal ini ditandai dengan masih adanya keluhan masyarakat yang disampaikan melalui media massa, sehingga dapat menimbulkan citra yang kurang baik terhadap aparatur pemerintah. Kepuasan Masyarakat terhadap Penyelenggara Pelayanan Publik, khususnya di lingkup Kementerian Agama sangat penting dilakukan dengan demikian kopetensi perlu perlu ditingkatkan Boreham (2014:5), yang meneliti mengenai "Teori kompetensi kolektif menantang individualisasi neo-liberal kinerja di tempat kerja." Pekerjaan contempory terkait pendidikan dan pelatihan merupakan kebijakan kompetensi kerja sebagai hasil dari kinerja individu di tempat kerja. Karya ini menyajikan kritik dari asumsi neoliberal, dengan alasan bahwa dalam banyak kasus kompetensi harus terencana sebagai atribut kelompok, tim, dan masyarakat. Ini mengusulkan teori kompetensi kolektif dalam hal (1) membuat rasa kolektif acara di tempat kerja, (2) mengembangkan dan menggunakan basis pengetahuan kolektif dan (3) mengembangkan rasa saling ketergantungan.

Motivasi kerja adalah hal yang menyebabkan, menyalurkan dan mendukung perilaku manusia, supaya mau bekerja giat dan antusias untuk mencapai hasil yang optimal. Motivasi semakin penting karena manajer membagikan pekerjaan pada bawahannya untuk dikerjakan dengan baik dan terintegrasi kepada tujuan yang diinginkan. Instansi pemerintahan tidak hanya mengharapkan pegawai mampu, cakap dan terampil tetapi yang terpenting mereka memiliki keinginan untuk bekerja dengan giat dan mencapai hasil kerja yang baik (Handoko, 2014:252).

Motivasi kerja akan sangat memengaruhi kinerja pegawai karena dengan motivasi kerja yang baik maka kinerja pegawai aan meningkat dan kepuasan masyarakat juga akan meningkat pula karena menurunnya tingkat kepercayaan masyarakat seharusnya mampu memotivasi para pegawai untuk memperbaiki pelayanan sehingga pada gilirannya akan meningkatkan kepuasan masyarakat.

\section{KAJIAN PUSTAKA}

\section{Manajemen Sumber Daya Manusia}

Manajemen pada dasarnya berasal dari kata to manage yang artinya mengatur. Manajemen adalah ilmu dan seni yang mengatur proses pemanfaatan sumber daya manusia dan sumbersumber daya lainnya secara efektif dan efesien untuk mencapai suatu tujuan tertentu (Hasibuan, 2013:141). Manajemen sumber daya manusia adalah seni dan ilmu pengadaan, pengembangan dan manfaat sumber daya manusia sehingga tujuan dapat dihasilkan secara daya guna dan kegairahan kerja (Manullang, 2014:32).

Menurut pendapat beberapa ahli tersebut, maka dapat disimpulkan bahwa manajemen sumber daya manusia merupakan ilmu yang mengatur sebuah pemanfaatan sumber daya manusia yang dikelola secara profesional guna mencapai tujuan individu maupun organisasi secara terprogram dan terpadu guna mengahsilkan sumber daya manusia yang berproduktif dan berkualitas serta mempunyai etos kerja dan loyalitas yang tinggi. 


\section{Konsep Kompetensi}

Mangkunegara (2012:113) mengemukakan bahwa kompetensi merupakan faktor mendasar yang dimiliki seseorang yang mempunyai kemampuan lebih, yang membuatnya berbeda dengan seseorang yang mempunyai kemampuan rata-rata atau biasa saja.

Menurut Mitrani dalam Usmara (2002:109) mengemukakan bahwa kompetensi adalah bagian kepribadian yang mendalam dan melekat kepada seseorang serta perilaku yang dapat diprediksi pada berbagai keadaan dan tugas pekerjaan.

Sedarmayanti (2012:126) mengemukakan bahwa kompetensi adalah karakteristik mendasar yang dimiliki seseorang yang berpengaruh langsung terhadap, atau dapat memprediksikan kinerja yang sangat baik. Dengan kata lain, kompetensi adalah apa yang oustanding performers lakukan lebih sering, pada lebih banyak situasi, dengan hasil yang lebih baik daripada apa yang dilakukan penilai kebijakan. Faktor lain yang harus diperhatikan adalah perilaku.

\section{Konsep Motivasi Kerja}

Motivasi berasal dari kata Motivation, yang artinya dorongan daya batin, sedangkan to motivate artinya mendorong untuk berprilaku atau berusaha. Motivasi dalam manajemen, lebih menitikberatkan pada bagaimana caranya mengarahkan daya dan potensi bawahan, agar mau bekerja sama secara produktif berhasil mencapai dan mewujudkan tujuan yang telah ditentukan.

Motivasi adalah hal yang menyebabkan, menyalurkan dan mendukung perilaku manusia, supaya mau bekerja giat dan antusias untuk mencapai hasil yang optimal. Motivasi semakin penting karena manajer membagikan pekerjaan pada bawahannya untuk dikerjakan dengan baik dan terintegrasi kepada tujuan yang diinginkan. Instansi pemerintahan tidak hanya mengharapkan pegawai mampu, cakap dan terampil tetapi yang terpenting mereka memiliki keinginan untuk bekerja dengan giat dan mencapai hasil kerja yang baik.

\section{Kepuasan Masyarakat}

Penyelenggara Pelayanan Publik yang selanjutnya disebut Penyelenggara adalah setiap institusi penyelenggara negara, korporasi, lembaga independen yang dibentuk berdasarkan undang-undang untuk kegiatan pelayanan publik, dan badan hukum lain yang di bentuk semata-mata untuk kegiatan pelayanan publik. Instansi Pemerintah adalah kementerian, lembaga, dan pemerintah daerah. Pembina adalah pimpinan lembaga negara, pimpinan kementerian, pimpinan lembaga nonkementerian, pimpinan lembaga komisi negara atau yang sejenis dan pimpinan lembaga lainnya, gubernur, bupati, dan walikota.

Unit Pelayanan Publik adalah satuan kerja di lingkungan instansi pemerintah yang memberikan pelayanan kepada masyarakat. Kinerja Unit Pelayanan Publik adalah tingkat keberhasilan unit pelayanan dalam memberikan pelayanan kepada masyarakat.

\section{METODE PENELITIAN}

penelitian ini menggunakan metode penelitian survey analitik dengan pendekatan cross sectional yang bertujuan untuk mengetahui pengaruh Kompetensi dan Motivasi Kerja terhadap Kinerja Pegawai dan Tingkat Kepuasan Masyarakat pada Pelayanan Terpadu Satu Pintu Kantor Kementerian Agama Kabupaten Tapin di Rantau.

\section{Populasi dan Sampel}

Populasi dalam penelitian ini adalah masyarakat yang melakukan kunjungan di Pelayanan Terpadu Satu Pintu Kantor Kementerian Agama Kabupaten Tapin di Rantau Kalimantan Selatan pada tahun 2020 berdasarkan rekapitulasi buku kunjungan tamu sebanyak 1.271 orang. 
Sedangkan sampel dalam penelitian ini menggunakan teknik porpusive sampling yakni penentuan sampel atas unsur kesengajaan yaitu seluruh masyarakat di wilayah kerja Pelayanan Terpadu Satu Pintu Kantor Kementerian Agama Kabupaten Tapin di Rantau Kalimantan Selatanberjumlah 93 orang.

\section{Teknik Pengumpulan Data}

Pada teknik pengumpulan data ini penulis menggunakan Studi Pustaka (Library Research), Studi Lapangan (Field Research), Observasi (Tinjauan Lapangan), dokumentasi dan Kuesioner

\section{Teknik Analisis Data}

1. Uji Validitas dan Reliabilitas

1) Uji Validitas

Uji validitas dilakukan untuk menguji validitas setiap pertanyaan angket. Skor setiap pertanyaan diuji validitasnya dikolerasikan dengan skor total seluruh pertanyaan

2) Uji Reliabilitas

Reliabilitas adalah indeks yang menunjukkan sejauh mana suatu alat pengukur dapat dipercaya atau dapat diandalkan. Pertanyaan yang sudah valid dilakukan uji reliabilitas dengan cara membandingkan rtabel dengan rhasil.

2. Uji Asumsi Klasik

\section{1) Uji Normalitas}

Uji Normalitas data ini digunakan untuk mengetahui kenormalan distribusi atau sebaran data.

2) Uji Linearitas

Uji linearitas dimaksudkan untuk memenuhi persyaratan regresi linear dalam meramalkan pengaruh antara variabel bebas dengan variabel terikat dan uji keberartian dari arah regresi tersebut.

3) Uji Multikoleniaritas

Uji multikoleniaritas bertujuan untuk menguji apakah model regresi ditemukan adanya korelasi antar variabel bebas atau independen.

4) Uji Heteroskedastisitas

Uji heteroskedastisitas bertujuan untuk menguji apakah dalam model regresi terjadi ketidaksamaan variance dari residual satu pengamatan ke pengamatan lain, jika variance dari residual satu pengamatan ke pengamatan lain berbeda maka disebut heteroskedastisitas.

\section{Analisis regresi Linier Berganda}

Analisis regresi linier berganda digunakan untuk mengetahui ada tidaknya pengaruh kompetensi, motivasi kerja dan kinerja pegawai terhadap kepuasan masyarakat pada Pelayanan Terpadu Satu Pintu Kantor Kementerian Agama Kabupaten Tapin di Rantau (Y).

\section{Pengujian Hipotesis}

1. Uji F

Untuk uji simultan (bersama-sama), digunakan Uji $\mathrm{F}$ yang dimaksudkan untuk menguji signifikansi pengaruh variabel-variabel independen Xi secara keseluruhan terhadap variabel $\mathrm{Y}$. 2. Uji t

Independent sample t-test adalah jenis uji statistika yang bertujuan untuk membandingkan ratarata dua grup yang tidak saling berpasangan atau tidak saling berkaitan. 
3. $\quad$ Uji ß (Pengujian Koefesien Beta)

Koefesien beta digunakan untuk mengetahui kekuatan masing-masing variabel bebas dalam menentukan dependent variabel.

\section{Lokasi dan Waktu Penelitian}

Penelitian ini dilakukan pada Pelayanan Terpadu Satu Pintu Kantor Kementerian Agama Kabupaten Tapin di Rantau. Semua data atau informasi yang digunakan dalam penelitian ini adalah data kuantitatif yang bersumber dari data primer yang diperoleh dari hasil kuesioner. Jadwal kegiatan merupakan rencana kegiatan yang akan dalam melakukan penelitian. Penelitian ini direncanakan selama 6 Bulan, yaitu dari bulan Maret s/d Agustus 2020.

\section{HASIL DAN PEMBAHASAN}

\section{Uji Validitas}

1) Kompetensi (X1)

Berdasarkan hasil uji validitas yang dilakukan terhadap 93 orang responden tentang kuesioner "Kompetensi (X1)" dapat diketahui bahwa nilai sig. seluruh item pernyataan $<0,05$ atau nilai Pearson Correlation $>0,300$ sehingga dapat dinyatakan pernyataan valid.

2) Motivasi Kerja (X2)

Berdasarkan hasil uji validitas yang dilakukan terhadap 93 orang tentang kuesioner "Motivasi Kerja (X2)" dapat diketahui bahwa nilai sig. seluruh item pernyataan $<0,05$ atau nilai Pearson Correlation $>0,300$ sehingga dapat dinyatakan pernyataan valid.

3) Kepuasan masyarakat (Y)

Berdasarkan hasil uji validitas yang dilakukan terhadap 93 orang responden tentang kuesioner "Kepuasan masyarakat (Y)" dapat diketahui bahwa nilai sig. seluruh item pernyataan $<0,05$ atau nilai Pearson Correlation $>0,300$ sehingga dapat dinyatakan pernyataan valid.

b. Uji Reliabilitas

Hasil uji reliabilitas hasil kuesioner penelitian dapat diketahui bahwa seluruh kuesioner dinyatakan reliable dengan klasifikasi Kompetensi (X1), Motivasi Kerja (X2), Kepuasan masyarakat (Y) reliabilitas tinggi.

Adapun hasil uji Multikoliniaritas dalam penelitian ini dapat dilihat pada tabel berikut ini.

Tabel 1. Uji Multikoleniaritas

\section{Coefficients $^{\mathbf{a}}$}

\begin{tabular}{|ll|l|l|}
\hline \multicolumn{2}{|l|}{ Model } & \multicolumn{2}{|l|}{$\begin{array}{l}\text { Collinearity } \\
\text { Statistics }\end{array}$} \\
\cline { 3 - 4 } & & Tolerance & VIF \\
\hline 1 & (Constant) & & \\
& X1 &, 147 & 6,824 \\
& X2 &, 147 & 6,796 \\
& & & \\
\hline
\end{tabular}

a. Dependent Variable: Y

Sumber: Output Statistik

Berdasarkan tabel diatas tersebut diketahui bahwa angka tolerance mempunyai nilai tidak lebih dari $10 \%$ dan nilai VIF tidak lebih dari 10 yang berarti tidak terjadi Multikoliniaritas antar variabel bebas tersebut. Uji heteroskedastisitas menggunakan metode grafik plot regression 
standart predicted value dengan regression stutentised residual. Hasil pengujian dapat dilihat pada gambar berikut:

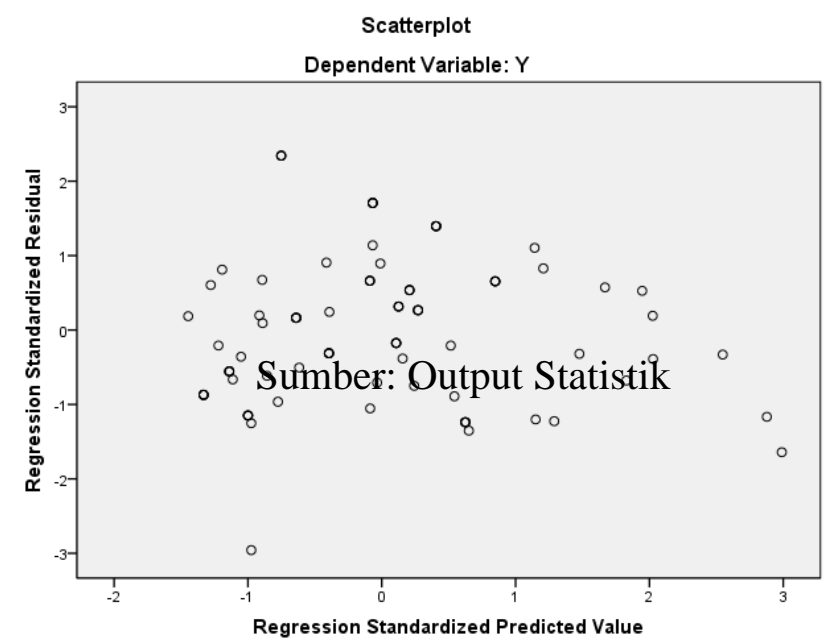

Gambar 1. Heteroskedastisitas

\section{Analisis regresi Linier Berganda Berdasarkan Variabel Y}

Analisis regresi linier berganda digunakan untuk mengetahui ada analisis pengaruh Kompetensi, Motivasi Kerja, terhadap Kepuasan masyarakat (Y). Pengaruh Kompetensi terhadap Kepuasan masyarakat (Y) Hasil penelitian menunjukkan bahwa pengaruh Kompetensi terhadap Kepuasan masyarakat (Y) dapat dilihat pada tabel berikut:

Tabel 2. Pengaruh Kompetensi (X1) terhadap Kepuasan Masyarakat (Y)

\section{Coefficients $^{\mathrm{a}}$}

\begin{tabular}{|ll|l|l|l|l|l|}
\hline \multirow{2}{*}{ Model } & & \multicolumn{2}{|l|}{$\begin{array}{l}\text { Unstandardized } \\
\text { Coefficients }\end{array}$} & $\begin{array}{l}\text { Standardized } \\
\text { Coefficients }\end{array}$ & \multirow{2}{*}{$\mathrm{t}$} & \multirow{2}{*}{ Sig. } \\
\cline { 2 - 5 } & & $\mathrm{B}$ & Std. Error & Beta & & \\
\hline 1 & (Constant) & $-2,506$ &, 668 & & $-3,753$ &, 000 \\
& X1 &,- 406 &, 157 &,- 161 & $-2,578$ &, 012 \\
\hline
\end{tabular}

a. Dependent Variable: Y

Sumber: Hasil Output SPSS Versi 18 (2020)

Hasil penelitian menunjukkan bahwa nilai prob. thitung (Sig.) dari variabel bebas sebesar $0,000<0,05$ sehingga dapat dikatakan bahwa ada pengaruh signifikan Kompetensi terhadap Kepuasan masyarakat (Y). Berdasarkan nilai thitung sebesar -2,578 tapi Kompetensi mempunyai pengaruh signifikan. Hal menunjukan bahwa walaupun pegawai memiliki kompetensi yang rendah, tapi pelayanan pada Pelayanan Terpadu Satu Pintu Kantor Kementerian Agama Kab. Tapin di Rantau harus tetap berjalan sebagaimana peraturan yang berlaku karena hal tersebut berpengaruh pada tingkat kepuasan masyarakat. 


\section{Pengaruh Motivasi Kerja terhadap Kepuasan masyarakat (Y)}

Hasil penelitian menunjukkan bahwa pengaruh Motivasi Kerja terhadap Kepuasan masyarakat (Y) dapat dilihat pada tabel berikut:

Tabel 3. Pengaruh Motivasi Kerja (X2) terhadap Kepuasan masyarakat (Y) Coefficients $^{\mathrm{a}}$

\begin{tabular}{|ll|l|l|l|l|l|}
\hline \multirow{2}{*}{ Model } & & \multicolumn{2}{|l|}{$\begin{array}{l}\text { Unstandardized } \\
\text { Coefficients }\end{array}$} & $\begin{array}{l}\text { Standardized } \\
\text { Coefficients }\end{array}$ & \multirow{2}{*}{ S } & \multirow{2}{*}{ Sig. } \\
\cline { 2 - 6 } & & B & Std. Error & Beta & & \\
\hline 1 & (Constant) & $-2,506$ &, 668 & & $-3,753$ &, 000 \\
& X2 &, 612 &, 053 &, 715 & 11,493 &, 000 \\
\hline
\end{tabular}

a. Dependent Variable: Y

Sumber: Hasil Output SPSS Versi 18 (2020)

Hasil penelitian menunjukkan bahwa nilai prob. thitung (Sig.) dari variabel bebas sebesar $0,012<0,05$ sehingga dapat dikatakan bahwa ada pengaruh signifikan Motivasi Kerja terhadap Kepuasan masyarakat (Y). Berdasarkan nilai thitung sebesar 11,493 menunjukan bahwa pegawai yang memiliki Motivasi Kerja yang tinggi akan berpengaruh pada meningkatnya Kepuasan Masyarakat pada Pelayanan Terpadu Satu Pintu Kantor Kementerian Agama Kab. Tapin di Rantau.

Berdasarkan uraian tersebut diatas, maka untuk mencapai tujuan pembangunan nasional yang telah ditetapkan, pemerintah sebagai penggerak dan pelaksana pembangunan memerlukan aparatur yang benar-benar dapat bekerja secara efektif dan efesien dan melaksanakan tugas pemerintah dan pembangunan. Dewasa ini salah satu tantangan terbesar yang dihadapi oleh pemerintah khususnya pemerintah daerah adalah bagaimana menampilkan aparatur yang baik, memiliki etos kerja yang tinggi, keunggulan kompetitif, dan kemampuan memegang teguh birokrasi dalam menjalankan tugas dan fungsinya dan memenuhi aspirasi masyarakat serta terbebas dari kolusi, korupsi dan nepotisme. Tantangan tersebut merupakan hal yang beralasan mengingat secara empirik masyarakat didaerah menginginkan agar aparat pemerintah dalam menjalankan tugas-tugasnya dapat bekerja secara optimal yang akhirnya dapat memberikan pelayanan yang terbaik terhadap masyarakat.

\section{KESIMPULAN DAN SARAN}

Berdasarkan hasil penelitian yang telah dilakukan mengenai Analisis Pengaruh Kompetensi dan Motivasi Kerja terhadap Kepuasan masyarakat pada Pelayanan Terpadu Satu Pintu Kantor Kementerian Agama Kabupaten Tapin di Rantau, dengan cara membagikan kuesioner terhadap 93 orang responden

1. Kompetensi berpengaruh signifikan terhadap Kepuasan masyarakat pada Pelayanan Terpadu Satu Pintu Kantor Kementerian Agama Kabupaten Tapin di Rantau.

2. Motivasi Kerja berpengaruh signifikan terhadap Kepuasan masyarakat pada Pelayanan Terpadu Satu Pintu Kantor Kementerian Agama Kabupaten Tapin di Rantau.

\section{Saran}

1. Sebaiknya bagi pegawai diharapkan dapat meningkatkan kompetensinya dalam melayani dan memahami keinginan masyarakat yang datang pada Pelayanan Terpadu Satu Pintu Kantor Kementerian Agama Kabupaten Tapin di Rantau. 
2. Perlunya penelitian yang jauh lebih dalam dengan menggunakan teknik analisis berbeda dan variabel yang jauh lebih luas untuk mengetahui faktor lain yang mampu mempengaruhi Kepuasan masyarakat pada Pelayanan Terpadu Satu Pintu Kantor Kementerian Agama Kabupaten Tapin di Rantau.

\section{DAFTAR PUSTAKA}

Amirullah. 2002. Perilaku Konsumen. Edisi Pertama. Cetakan Pertama. Jakarta : Graha Ilmu. Anwar Prabu Mangkunegara. 2014. Evaluasi Kinerja SDM. Bandung : PT. Refika Aditama.

As'ad, Muhammad. 1987. Psikologi Industri, Edisi Ketiga. Yogyakarta : Penerbit Lyberti.

Boreham, N. 2004. A Theory of Collective Competence Challenging the Neoliberal Individualisation of Performance at Work. Journal of Management Development. Vol. 27 No.1, hal.5-7.

Burns, R. B. 2013. Konsep Diri: Teori, Pengukuran, Perkembangan, dan Perilaku (Terjemahan Eddy). Jakarta : Arcan.

Dunnett NP, Kingsbury N. 2004. Planting Green Roofs and Living Walls. Portland (OR) : Timber Press.

Fadel, Muhammad dan K. Toruan Rayendra L. 2012. Reinventing Government (Pengalaman Dari Daerah). Jakarta : PT. Elex Media Komputindo

Gitosudarmo, Indriyo dan I Nyoman Sudita. 2014. Perilaku Keorganisasian. Yogyakarta : BPFE Yogyakarta.

Handoko, T. Hani. 2014. Manajemen Personalia dan Sumber Daya Manusia. Yogyakarta : BPFE.

Hutapea, P. dan Thoha, N. 2012. Kompetensi Plus. Jakarta : Gramedia Pustaka Utama.

Keputusan Menteri Agama Republik Indonesia Nomor 109 Tahun 2017 Tentang Standar Pelayanan Pada Kementerian Agama

Keputusan Menteri Agama Republik Indonesia Nomor 90 Tahun 2018 Tentang Petunjuk Pelaksanaan Penyelenggaraan Pelayanan Terpadu Kementerian Agama

Kusriyanto, Bambang. 2012. Meningkatkan Produktifitas Karyawan. Jakarta : PT. Pustaka Binaman Pressindo.

Malayu Hasibuan, S.P. 2013. Manajemen Sumber Daya Manusia. Edisi Revisi, Jakarta : PT. Bumi Aksara.

Mangkunegara, A.A., \& Anwar, P. 2012. Manajemen Sumber Daya Manusia. Bandung : PT. Remaja Rosdakarya.

Manullang. 2014. Manajemen Sumber Daya Manusia. Yogyakarta : Gadjah Mada University Press

Mathis, Robert L dan John H. Jackson, 2012. Manajemen Sumber Daya Manusia. Buku 1, Alih Bahasa: Jimmy Sadeli dan Bayu. Prawira Hie, Jakarta : Salemba Empat.

Monks, F.J., Knoers, A.M.P., Hadinoto, S.R. 20013. Psikologi Perkembangan. Yogyakarta : Gajah Mada University Press.

Pasolong, Harbani. 2012. Teori Administrasi Publik. Yogyakarta : Alfabeta

Peraturan Menteri Agama Republik Indonesia Nomor 65 Tahun 2016 Tentang Pelayanan Terpadu Pada Kementerian Agama

Peraturan Menteri Pendayagunaan Aparatur Negara Dan Reformasi Birokrasi Republik Indonesia Nomor 14 Tahun 2017 Tentang Pedoman Penyusunan Survei Kepuasan Masyarakat Unit Penyelenggara Pelayanan Publik

Peraturan Pemerintah Nomor 96 Tahun 2012 tentang Pelaksanaan Undang-Undang Nomor 25 Tahun 2009 tentang Pelayanan Publik

Rizky, Ahmad S. 2012. Manajemen Pengganjian Karyawan Perusahaan. Jakarta : Gramedia Media Utama 
Sedarmayanti, 2012. Manajemen Sumber Daya Manusia. Jakarta : Refika Aditama Eresco

Sianipar, J.P.G. 2015. Manajemen Pelayanan Masyarakat. Jakarta : Lembaga Administrasi Negara Republik Indonesia.

Simamora, Henry. 2015. Manajemen Sumber Daya Manusia. Yogyakarta : STIEY

Soekanto, Soerjono. 2011. Sosiologi Suatu Pengantar. Jakarta : PT. Rajagrafindo Persada.

Soemanto, Wasty. 1987. Psikologi Pendidikan. Jakarta: Bina Aksara

Sudarmanto. 2014. Kinerja dan Pengembangan Kompetensi SDM. Yogjakarta : Pustaka Pelajar

Susanti, I., Syairozi, M. I., \& Lukman, H. Y. W. (2021). Analisis Sistem Manajemen Dalam Pengelolaan Bumdes Di Desa Bluluk. Jurnal Sains Sosio Humaniora, 5(2), 701-710.

Syairozi, M. I. (2017, September). ANALISIS PAJAK DAN VARIABEL MAKROEKONOMI TERHADAP PENERIMAAN PAJAK PERNGHASILAN. In Seminar Nasional Sistem Informasi (SENASIF) (Vol. 1, No. 1, pp. 338-350).

T., Enas, U., Zunaidi, A., Pribadi, Y., Syairozi, I., Andri, B., Uliansyah, A., Sunyoto, E., Sijabat, R., Sarasi, V., Sugiri, D., Hastanti, A., Rahayu, D. C., Pangestuti, A. A., \& Pratama, S. (2021). KEUANGAN NEGARA. www.penerbitwidina.com

Undang-Undang Republik Indonesia Nomor 5 Tahun 2014 tentang Aparatur Sipil Negara.

Undang-Undang Republik Indonesia Nomor 25 Tahun 2009 Pelayanan Publik.

Usmara, A. 2002. Paradigma Baru : Manajemen Sumber Daya Manusia. Cetakan keempat. Yogyakarta : Amara Books.

Winardi. 2012. Manajemen Sumber Daya Manusia, Edisi Ketiga, Jakarta : Rineka Cipta. 